\title{
Isolation and Identification of Two $\beta$-Hydroxy-pyridine Derivatives from the Nondialyzable Melanoidin-hydrolyzate ${ }^{\dagger}$
}

\author{
Hironobu Tsuchida, Masahiko Kōmoto, Hiromichi Kato* \\ and Masao FujImaki* \\ Department of Agricultural Chemistry, Faculty of Agriculture, Kobe University, Kobe \\ * Department of Agricultural Chemistry, Faculty of Agriculture, Tokyo University, Tokyo
}

Received September 8, 1972

\begin{abstract}
The hydrolyzate of the melanoidin prepared from glucose-ammonia system (kept in $\mathrm{pH} 5.3 \sim 6.0$ during the reaction) was fractionated into the two fractions of non-adsorbate and adsorbate on Amberlite IR-120 ( $\mathrm{H}^{+}$-form). In the present paper, the adsorbed fraction (Fraction B) was examined.

Paper chromatographic examination of the Fraction B indicated the presence of at least eight compounds positive to diazotized sulphanilic acid reagent. The two compounds of them (indicated orange and orange-yellow color) were isolated and identified as 2-methyl-5hydroxy-pyridine and 2-hydroxymethyl-5-hydroxy-pyridine, respectively.

It is probable that these compounds would loosely be bound as a small moiety in the melanoidin molecule.
\end{abstract}

The melanoidins formed by the reaction between reducing sugars and amino compounds vary considerably in their properties according to the condition of formation, and these brown substances are a complicated heterogeneous compound being highly dispersive in molecular weight. Also in regard to the melanoidins formed from glucose-ammonia system, the same feature as above is recognized. The melanoidin prepared from this reaction system under a certain condition has been generally used as an edible pigment, so-called "ammoniacaramel," because of its desirable properties.

Hitherto, many lower molecular compounds among the reaction products in reducing sugarammonia system have been isolated and identified $^{1}$; for example, such compounds as imidazoles, pyrazines and pyridines. These information have considerably contributed to elucidation of some parts of the aminocarbonyl reaction mechanism. However, whether the above heterocyclic compounds are incorporated into melanoidin molecule on its formation or not, have never been elucidated.

\footnotetext{
$\dagger$ Melanoidin Produced from the Reaction of Glucose and Ammonia. Part III.
}

As described previously, ${ }^{2}$ the melanoidin prepared from glucose and ammonia according to the preparation-condition of ammoniacaramel could be fractionated into six fractions (F 1 F 6) by DEAE-cellulose column chromatography. Recently, the authors ${ }^{3}$ reported on sugars produced by hydrolysis of the nondialyzable melanoidin and the fractionated melanoidins.

In the present paper, the compounds given positive test to diazolized sulphanilic acid reagent in the nondialyzable melanoidin- and the fractionated melanoidins-hydrolyzates were examined by paper chromatography (PPC), and two $\beta$-hydroxy-pyridine derivatives among these compounds detected were isolated and respectively identified as 2-hydroxy-methyl-5hydroxy-pyridine and 2-methyl-5-hydroxypyridine.

\section{EXPERIMENTAL}

Infrared spectra were determined as potassium bromide tablets using the Hitachi EPI-S 2 type infrared spectrometer. Absorption spectra in UV-region were recorded with the Hitachi EPS-2 type recording spectrometer. Paper chromatographic data were obtained by ascending development on Toyo Roshi 
No. 50 filter paper using solvent systems as follows: 1) $n$-propanol-ethyl acetate-water $(7: 1: 2 \mathrm{v} / \mathrm{v} / \mathrm{v})$, 2) acetone-chloroform-water-28\% aqueous ammonia $(30: 5: 4: 0.4 \mathrm{v} / \mathrm{v} / \mathrm{v} / \mathrm{v})$. Authentic 2-methyl-5hydroxy-pyridine and 2-hydroxymethyl-5-hydroxypyridine were prepared according to Aso's procedure."

\section{Preparation of melanoidin}

i) Nondialyzable melanoidin. As previously described, ${ }^{2}$, nondialyzable melanoidin was obtained by dialyzing the ethanol-insoluble fraction of the browning reaction mixture prepared from glucose and ammonia according to the preparation-condition of ammoniacaramel.

ii) Fractionated melanoidins. In accordance with the procedure described previously, ${ }^{2,31}$ five melanoidins ( F 2, F 3, F 4, F 5 and F 6) were obtained by fractionating the nondialyzable melanoidin on DEAE-cellulose column using diluted acetic acid solutions and $0.1 \mathrm{~N}$ hydrochloric acid solution as eluent.

Acid hydrolysis of melanoidins and fractionation of the melanoidin hydrolyzates. The nondialyzable melanoidin $(10 \mathrm{~g})$ was dissolved in $150 \mathrm{ml}$ of $0.1 \mathrm{~N}$ hydrochloric acid and heated at $100^{\circ} \mathrm{C}$ for $7 \mathrm{hr}$. The hydrolyzate was evaporated under reduced pressure to dryness. To the dried matter was added $50 \mathrm{ml}$ of water, and the solution was reevaporated under reduced pressure. The procedure was repeated until hydrochloric acid could not be detected in the hydrolyzate. The hydrolyzate freed from hydrochloric acid was dissolved in $500 \mathrm{ml}$ of water and filtered from insoluble matter. The filtrate was passed through the column of Amberlite IR-120 ( $\mathrm{H}^{+}$-form, $\left.150 \mathrm{ml}\right)$ and washed with water until the washing was no longer acidic. The adsorbate on the ion exchanger was then eluted with $1000 \mathrm{ml}$ of $9 \%$ aqueous ammonia. After the effluent was evaporated to dryness, the obtained matter was extracted several times with $15 \mathrm{ml}$ of methanol. The extract (Fraction B) was obtained in the yield of $0.691 \mathrm{~g}$.

In accordance with the above method, $100 \mathrm{mg}$ of each of the fractionated melanoidins (F 2, F 3, F4, F5 and $F$ 6) was hydrolyzed and treated with Amberlite IR-120 ( $\mathrm{H}^{+}$-form, $\left.2 \mathrm{ml}\right)$. The fraction corresponding to the Fraction $\mathrm{B}$ was obtained by eluting the adsorbate with $9 \%$ aqueous ammonia and then extracting with methanol.

Isolation of two $\beta$-hydroxy-pyridine derivatives. Fraction $B(0.55 \mathrm{~g}$ in $2 \mathrm{ml}$ of water $)$ was applied on DEAE-cellulose column $(2.5 \times 20.0 \mathrm{~cm})$ packed with water, and eluted stepwise with water $(400 \mathrm{ml})$ and $0.05 \mathrm{M}$-acetic acid solution $(500 \mathrm{ml})$. The elution pattern is shown in Fig. 3. Fraction $\mathrm{B}_{3}$ and fraction $\mathbf{B}_{4}$ were separately evaporated under reduced pressure. Fraction $\mathrm{B}_{3}$ was subjected to the preparative silica gel thin-layer chromatography (TLC) with solvent system fo ethyl acetate-benzene $(1.5: 1 \mathrm{v} / \mathrm{v})$, and the zone including compound B 1 was scraped out and then eluted with solvent mixture (ethyl acetate-ethanol, 1: $1 \mathrm{v} / \mathrm{v}$ ). After evaporation of the solvent, compound B 1 was obtained as needle crystal ( $\mathrm{mp} 165 \sim 167^{\circ} \mathrm{C}$ ) in about $4 \mathrm{mg}$ yield. Compound $\mathrm{B} 2$ included in fraction $\mathrm{B}_{4}$ was isolated by the preparative PPC with solvent system (2), followed by the preparative silica gel TLC with solvent system of ethyl acetate-ethanol $(10: 1 \mathrm{v} / \mathrm{v})$. The purified compound B 2 was obtained in about $3 \mathrm{mg}$ yield.

\section{RESULTS AND DISCUSSION}

According to the scheme shown in Fig. 1, nondialyzable melanoidin-hydrolyzate was fractionated into Fraction $\mathrm{A}$ and Fraction $\mathrm{B}$ by using Amberlite $\mathrm{IR}-120\left(\mathrm{H}^{+}\right.$-form). In the previous paper, ${ }^{3 \prime}$ it was reported that Fraction A composed largely of sugars.

Though Fraction B dealt with in this experiment contained considerable amounts of coloring substances, it would be expected that some nitrogenous compounds other than the coloring substances should be present in the Fraction.

Paper chromatographic examination of the Fraction B indicated the presence of at least eight compounds positive to diazotized sulphanilic acid ${ }^{5}$ and also Fraction B from each of the fractionated melanoidins gave similar pattern to that of Fraction B from the nondialyable melanoidin, as shown in Fig. 2. Compound B 4 (detected as red spot) was detected as larger spot than the other spots. The compound was paper chromatographically identical with 4(5)-(2,3,4-trihydroxy-butyl)imidazole, which was already isolated from glucose-ammonia reaction mixture by Kōmoto. $^{6)}$ (Fig. 2 and Fig. 4). Isolation and identification of compound B 4 will be detailed in the otherwise paper.

Compound B 1 and compound B 2 were distinctly detected only when considerable quantities of Fraction B were applied on the filter paper. These compounds gave respectively orange and orange-yellow color, which were different from the color reaction to imidazole derivatives isolated from glucoseammonia system. Examination of Fraction 
Nondialyzable Melanoidin ( $10 \mathrm{~g}$ )

Hydrolyzate

-hydrolysis with $0.1 \mathrm{~N}$ hydrochloric acid

-evaporated, dissolved in water $(500 \mathrm{ml})$, filtered

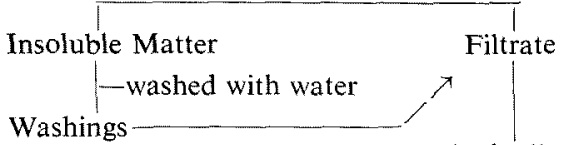

Washings

Amberlite IR-120 ( $\mathrm{H}^{+}$-form, $\left.150 \mathrm{ml}\right)$

Adsorbate
$\begin{gathered}\text { Eluted with } 9 \% \\ \text { aqeuous ammonia }\end{gathered}$
$\mid$-evaporated, dried $\quad \begin{aligned} & \text { Eluate } \\ & \text {-evaporated to } 200 \mathrm{ml} \text {, } \\ & \text { decolorized with charcoal }\end{aligned}$

Dried Matter

White Powder (Fraction A)*

- extracted with methanol

Methanol Extract (Fraction B)

$(0.691 \mathrm{~g})$

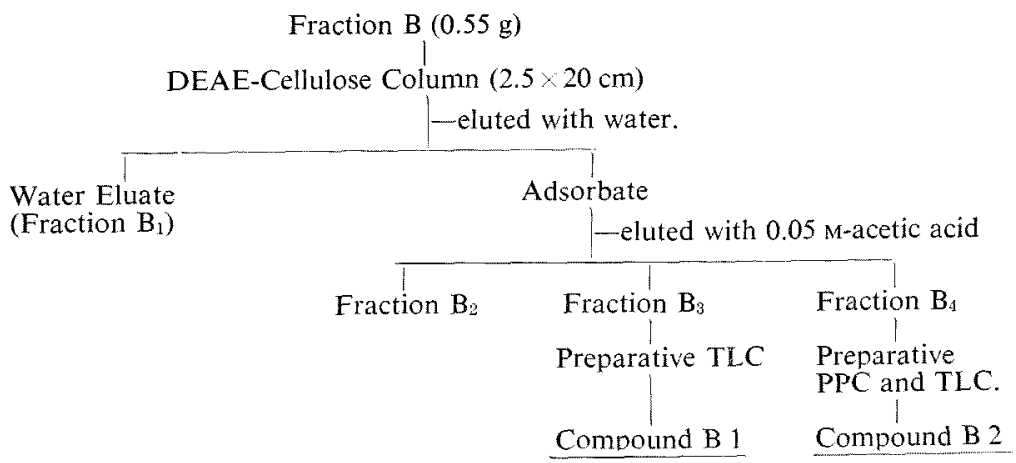

FIG. 1. Fractionation of Nondialyzable Melanoidin-Hydrolyzate and Isolation of Compound B 1 and Compound B 2.

* Fraction A was examined in the previous paper.

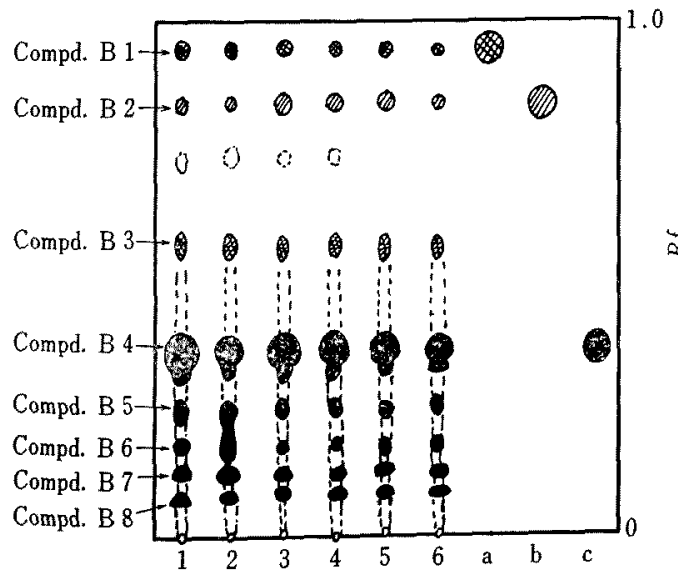

FIG. 2. Paper Chromatograms of Fraction B from Hydrolyzates of Nondialyzable Melanoidin and Fractionated Melanoidins. ${ }^{2,3}$ $\leftarrow 1$ : Fraction $\mathrm{B}$ obtained from the nondialyzable melanoidin

2: Fraction $B$ obtained, from the fractionated melanoidin $\mathrm{F} 2$

3: Fraction $\mathrm{B}$ obtained from the fractionated melanoidin $F 3$

4: Fraction $B$ obtained from the fractionated melanoidin $F 4$

5: Fraction B obtained from the fractionated melanoidin $F 5$

6: Fraction $B$ obtained from the fractionated melanoidin $F 6$

a: Authentic 2-methyl-5-hydroxy-pyridine

b: Authentic 2-hydroxymethyl-5-hydroxy-pyridine

c: Authentic 4(5)-(2,3,4-trihydroxy-butyl)-imidazole

Solvent; $n$-propanol-ethyl acetate-water $(7: 1: 3$ $\mathrm{v} / \mathrm{v} / \mathrm{v}$ ) Spraying reagent: diazotized sulphanilic acid reagent

- red to orange-red color

: orange color

紋: yellow to orange-yellow color 


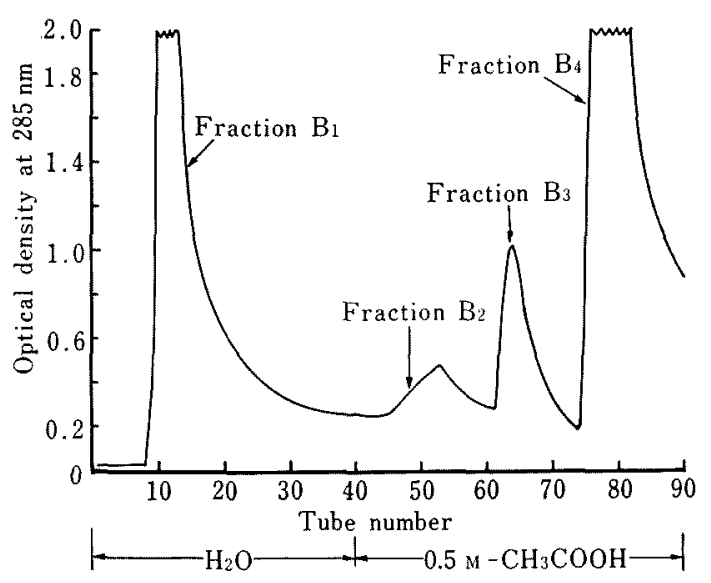

Fig. 3. Elution Pattern of Fraction B on DEAECellulose Column.

Fraction B $(0.55 \mathrm{~g})$ was applied on DEAE-cellulose column $(2.5 \times 20 \mathrm{~cm})$, and eluted with water $(400 \mathrm{ml})$ and $0.5 \mathrm{M}$-acetic acid solution $(500 \mathrm{ml})$. Eluate was cut in $10 \mathrm{ml}$.

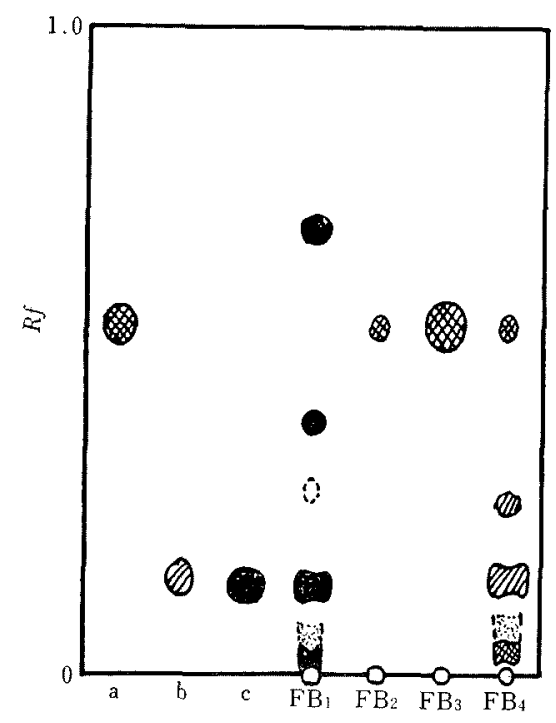

FIG. 4. Paper Chromatogram of Four Fractions Obtained from Fraction B by DEAE-Cellulose Column Chromatography.

$F_{B_{1}}$ : Fraction $B_{1}, F_{2}$ : Fraction $B_{2}, F_{3}$ : Fraction $B_{3}$, $\mathrm{FB}_{4}$ : Fraction $\mathrm{B}_{4}$.

a: Authentic 2-methyl-5-hydroxy-pyridine

b: Authentic 2-hydroxymethyl-5-hydroxy-pyridine

c: Authentic 4(5)-(2,3,4-trihydroxy-butyl)-imidazole

Solvent: acetone-chloroform-water-28\% aqueous ammonia (30:5:4:0.4 v/v/v/v) (Solvent 2)

Spraying reagent: diazotized sulphanilic acid reagent

: red to orange-red color

: orange color

: yellow to orange-yellow color
B by DEAE-cellulose column gave the result that on eluting with water, these compounds were adsorbed on the anion exchanger, but the compounds indicated red or red-orange color were not adsorbed. This is apparent from the paper chromatogram (shown in Fig. 4) of the fraction obtained in Fig. 3. Furthermore, UV-spectra of the both crude compound B 1 and compound B 2 separated by the preparative PPC using solvent system (2) showed maximum absorption at the range

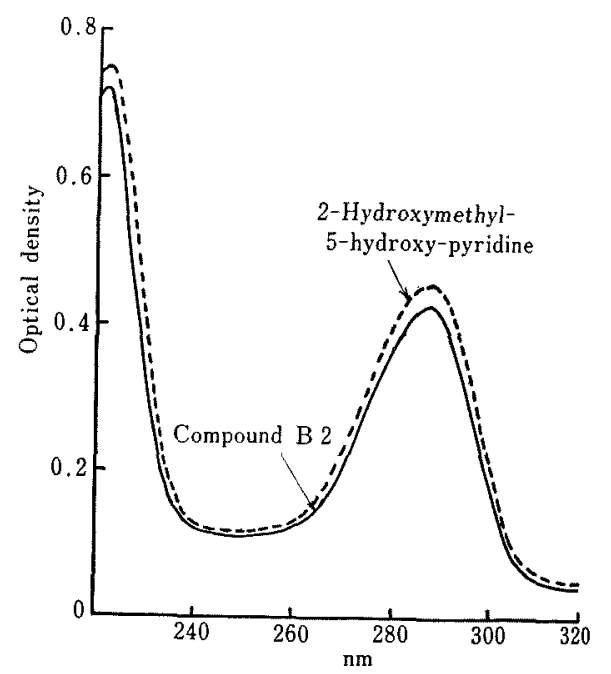

FIG. 5. UV-Spectra of Compound B 1 and Authentic 2-Methyl-5-hydroxy Pyridine.

Solvent: methanol

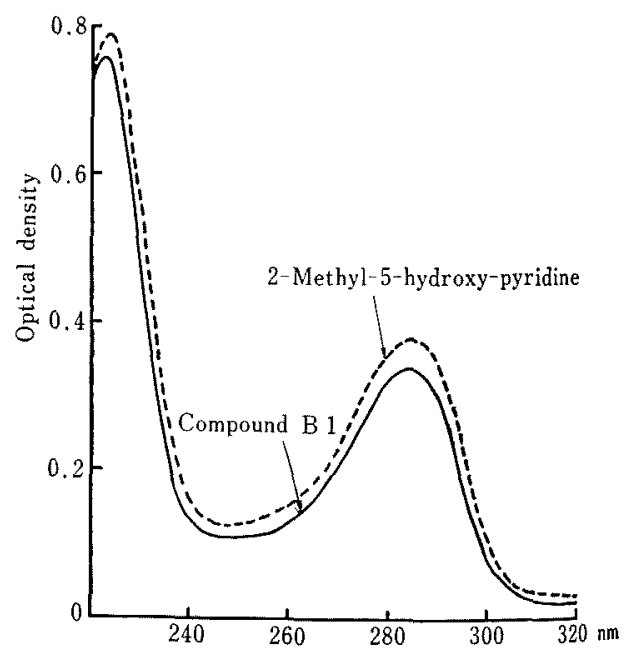

FIG. 6. UV-Spectra of Compound B 2 and Authentic 2-Hydroxymethyl-5-hydroxy Pyridine.

Solvent: methanol 
from $280 \mathrm{~nm}$ to $290 \mathrm{~nm}$, corresponding to a known transition in $\beta$-hydroxy-pyridines.

Although it was anticipated that the amount of these compounds in Fraction B should be very small, isolation and identification of these compounds were attempted. The elution pattern of Fraction $B$ on DEAE-cellulose are shown in Fig. 3. From the paper chromatographic examination of these fractions obtained above, it was elucidated that compound $\mathrm{B} 1$

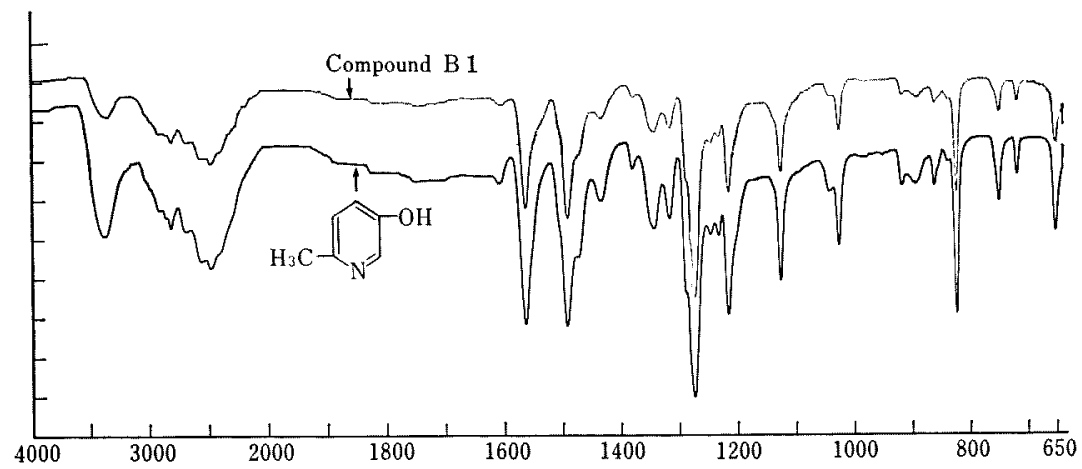

FIG. 7. IR-Spectra of Compound B 1 and Authentic 2-Methyl-5-hydroxy-pyridine.

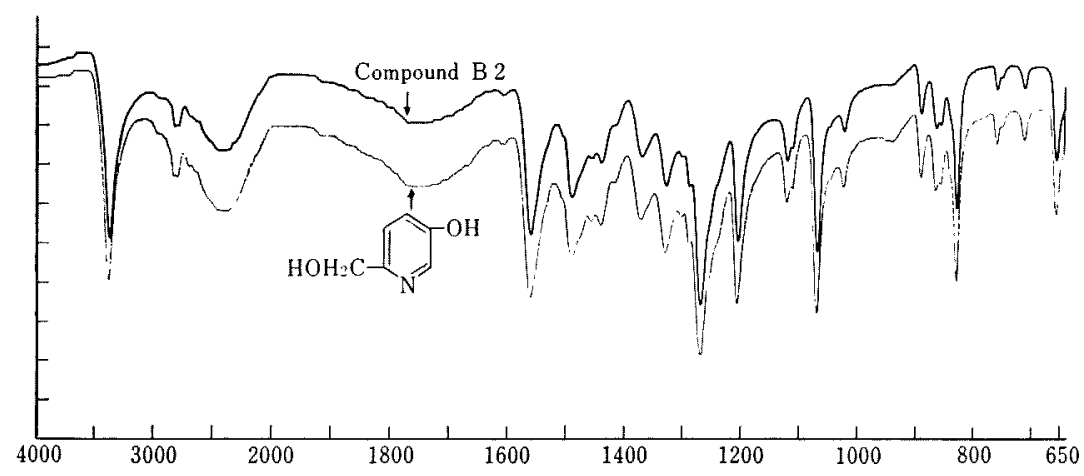

FIG. 8. IR-Spectra of Compound B 2 and Authentic 2-Hydroxymethyl-5-Hydroxy-pyridine.

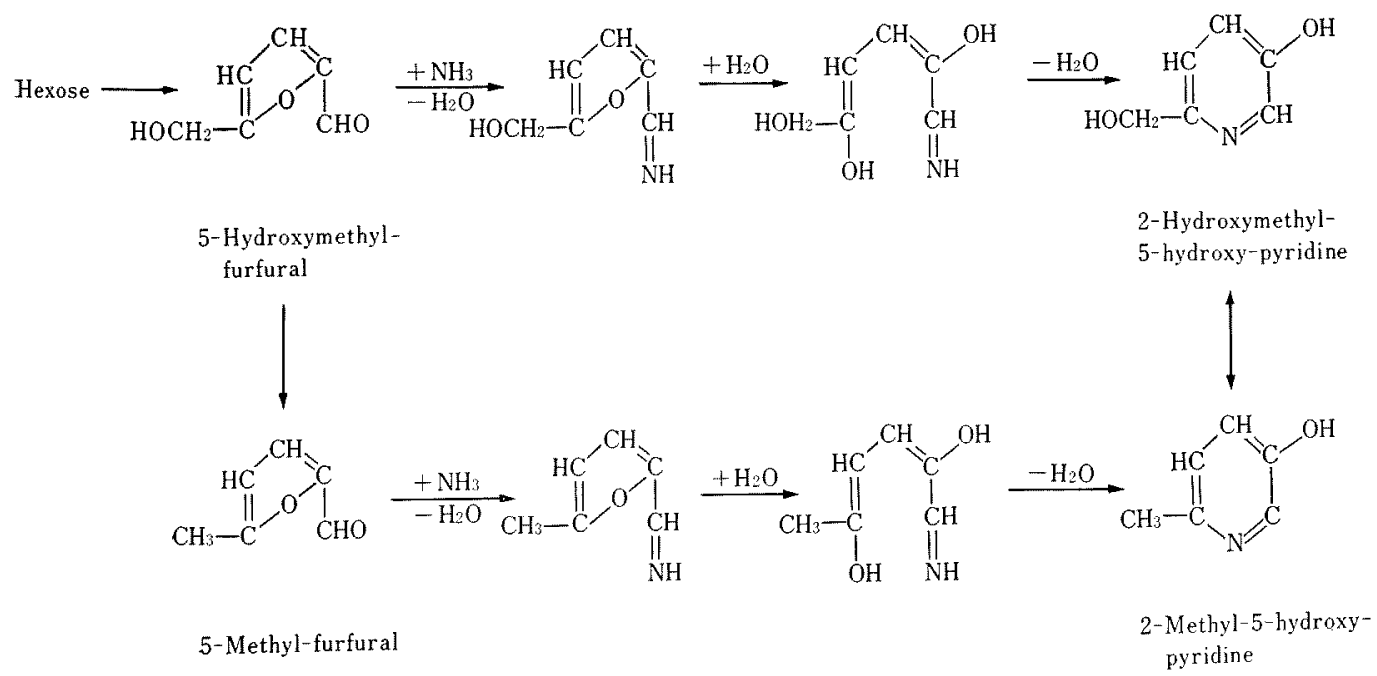

FIG. 9. Formation Mechanism of B-Hydroxy-pyridines Proposed by Aso. 
was mainly eluted in fraction $\mathrm{B}_{3}$ and compound B 2 in fraction B 4 . (shown in Fig. 4). However, fraction $B_{4}$ included especially large amounts of browning substances. Therefore, compound $\mathbf{B} 1$ included in fraction $\mathbf{B}_{3}$ was purified by the preparative TLC, and compound $\mathrm{B} 2$ in fraction $\mathrm{B}_{4}$ was purified by combination of the preparative PPC and TLC. The purified compound B 1 and compound B 2 were paper chromatographically agreed closely with authentic 2-methyl-5-hydroxy-pyridine and 2-hydroxymethyl-5-hydroxy-pyridine, respectively. Also, the UV-spectra and IRspectra of compound B 1 and authentic 2methyl-5-hydroxy-pyridine, or those of compound B 2 and authentic 2-hydroxymethyl-5hydroxy-pyridine were identical, respectively. (Figs. 5, 6, 7 and 8). From the above results, compound B 1 and compound B 2 were respectively identified with 2-methyl-5-hydroxypyridine and 2-hydroxymethyl-5-hydroxypyridine.

The $\beta$-hydroxy-pyridine derivatives present in melanoidin molecule have not been yet reported. Enders ${ }^{\mathrm{T}}$ detected pyridines in zinc powder distillation products of the insoluble melanoidin prepared from glucose-glycine system, but he was unsuccessful to isolate and identify any pyridines.

Hitherto, some reports on formation of pyridine derivatives in glucose-ammonia system were already published: pyridine, ${ }^{8)}$ $\alpha$-picoline, ${ }^{97}$ and such $\beta$-hydroxy-pyridines, ${ }^{4}$, as 2-methyl-5-hydroxy-pyridine, 2-hydroxymethyl-5-hydroxy-pyridine and 2-methyl-5,6dihydroxy-pyridine were isolated and identified. Especially, investigation on $\hat{\beta}$-hydroxy-pyridine derivatives were ago detailed by Aso, ${ }^{4,10)}$ and he assumed that the two $\beta$-hydroxy-pyridines in glucose-ammonium salts system would be formed according to such the mechanism as shown in Fig. 9.

On the other hand, Paulsen and Todt ${ }^{11}$ reported that in weak acid solution, 5-amino5-deoxy-hexoses gave readily Amadori rearrangement product, as well as some $\beta$-hydroxy-pyridines (for example, 2-hydroxymethyl-5-hydroxy-pyridine). Subsequently,

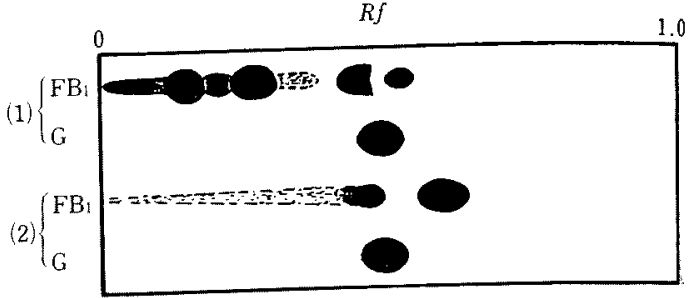

FIG. 10. Paper Chromatograms of Ninhydrin-positive Compounds in Fraction $\mathrm{B}_{1}$

$\mathrm{FB}_{1}$ : Fraction $\mathrm{B}_{1}$

$\mathrm{G}:$ glucosamine

(1) : ninhydrin reagent as spraying reagent

(2): aniline hydrogen phthalate reagent as spraying reagent

Solvent: $n$-butanol-pyridine-water $(4: 6: 3 \mathrm{v} / \mathrm{v} / \mathrm{v})$

Inouye et $a l .{ }^{12)}$ described that the antibiotic nojirimycin (5-amino-sugar) formed 2-hydroxymethyl-5-hydroxy-pyridine on mild treatment with acid.

Fraction $\mathrm{B}_{1}$ obtained above contained several ninhydrin-positive compounds (Fig. 10), although presence of 5-amino-sugar would not be expected. Therefore, the ninhydrinpositive fractions separated by preparative PPC were treated with the same hydrolysiscondition as described above and examined by PPC, but any $\beta$-hydroxy-pyridine was not detected. From the result, it would be assumed that the $\beta$-hydroxy-pyridines isolated from the melanoidin-hydrolyzate would not be formed from the ninhydrin-positive compounds, which may be a kind of amino-sugar, but the pyridines would perhaps be formed according to such the mechanism as shown in Fig. 9 and then incorporated into the melanoidin molecule. Amounts of these compounds in the melanoidin are so small that it may be impossible to say whether these compounds are present as a molecular skeleton in the melanoidin. However, from the fact that the two $\beta$-hydroxy-pyridines obtained above have been detected also in each fractionated melanoidin-hydrolyzate, it is presumed that these compounds are not present probably as an inclusion compound but bind chemically as a small moiety of the melanoidin molecule. Furthermore, hydrolysis experiment showed that even on boiling the fractionated melanoidins in aqueous solution, the $\beta$-hydroxy- 
pyridines were produced. The fact suggests that these compounds would loosely be bound in the melanoidin molecule.

\section{REFERENCES}

1) K. J. Kort, "Advances in Carbohydrate Chemistry and Biochemistry," Vol. 25, ed. by S. Tipson and D. Horton, Academic Press Inc., New York. N.Y., 1970, p. 311.

2) H. Tsuchida and M. Komoto, Proc. Res. Soc. Japan Sugar Refineries' Technologists, 21, 88, (1969).

3) H. Tsuchida and M. Komoto, Nippon Nogeikagaku Kaishi, 46, 561 (1972).

4) K. Aso, Nippon Nogeikagaku Kaishi, 15, 629
(1939).

5) B. N. Ames and U. K. Michell, J. Am. Chem. Soc., 74, 252 (1952).

6) M. Komoto, Nippon Nogeikagaku Kaishi, 36, 464 (1962).

7) C. Enders, Kolloid-Z., 85, 74 (1939).

8) P. Brandes and C. Stoehr, J. Prakt. Chem., (2), 54, 481 (1896).

9) B. K. Davison and L. F. Wiggins, Chen. Ind. (London), 1956, 982.

10) K. Aso, Nippon Nogeikagaku Kaishi, 16, 253 (1940).

11) H. Paulsen and K. Todt, Chem. Ber., 99, 3450 (1966).

12) S. Inouye, T. Tsuruoka, T. Ito and T. Niida, Tetrahedron, 23, 2125 (1968). 